\title{
EVALUASI KOMPONEN KONDISI FISIK ATLET KARATE
}

\author{
EVALUATION OF THE PHYSICAL CONDITION OF A KARATE ATHLETES \\ 1*Suprianto Kadir, ${ }^{2}$ Hermiten Dulanimo, \\ ${ }^{3}$ Arib B. Usman, ${ }^{4}$ Edy Dharma Putra Duhe, ${ }^{5}$ Syarif Hidayat \\ ${ }^{1 *, 2,3}$ Pendidikan Kepelatihan Olahraga, Fakultas Olahraga dan Kesehatan Universitas Negeri Gorontalo
}

Kontak koresponden: suprianto.kadir@ung.ac.id

\begin{abstract}
ABSTRAK
Penelitian ini bertujuan untuk mengevaluasi komponen kondisi fisik atlet Karate Pusat Pendidikan dan Latihan Pelajar (PPLP) Provinsi Gorontalo tahun 2021. Metode penelitian menggunakan deskriptif kuantitatif. Penarikan sampel menggunakan teknik total sampling. Adapun Sampel yang dimaksud merupakan atlet Karate PPLP Provinsi Gorontalo tahun 2021 yang berjumlah 13 orang terdiri dari 5 putri dan 8 putra. Instrumen pengumpulan data yang digunakan berupa tes dan pengukuran yang meliputi: 1) $\mathrm{VO}_{2} \mathrm{Max}$ menggunakan Multistage Fitness Test (Bleep Test); 2) Kekuatan otot lengan menggunakan push up selama 30 detik; 3) Kekuatan otot perut menggunakan sit up 30 detik;4) Kecepatan reaksi menggunakan alat beem 5) Kelincahan menggunakan shuttle run; 6) Power otot tungkai menggunakan standing board jump; dan 7) Kelentukan menggunakan sit and reach. Teknik analisis data menggunakan mean dan presentase kategori. Adapun hasil yang diperoleh yakni rata-rata nilai $\mathrm{VO}_{2} \mathrm{Max}$ atlet putra dan putri dalam kategori "Baik". Kekuatan otot lengan atlet putra maupun putri masih dalam kategori "Cukup". Kekuatan otot perut atlet putra rata-rata dalam kategori "Baik" dan atlet putri dalam kategori "Cukup". Kecepatan reaksi atlet putra dalam kategori "Baik Sekali" sedangkan atlet putri dalam kategori "Baik. Komponen kelincahan atlet putra dan putri dalam kategori "Baik". Komponen power otot tungkai atlet putra dan putri dalam kategori "Baik Sekali". Kelentukan atlet putra dalam kategori "Baik" dan putri dalam kategori "Baik Sekali".
\end{abstract}

Kata Kunci: evaluasi; komponen fisik; Karate

\section{ABSTRACT}

This study aims to evaluate the components of the physical condition of the Karate athletes of the Gorontalo Province Student Education and Training Center (PPLP) in 2021. The research method uses quantitative descriptive. Sampling using total sampling technique. The sample in question is the PPLP Gorontalo Province Karate athlete in 2021, totaling 13 people consisting of 5 women and 8 sons. The data collection instruments used were in the form of tests and measurements which included: 1) VO2Max using the Multistage Fitness Test (Bleep Test); 2) Arm muscle strength using push ups for 30 seconds; 3) Strength of abdominal muscles using 30 second sit ups; 4) Reaction speed using the beem tool 5) Agility using the shuttle run; 6) Power leg muscles using a standing board jump; and 7) Flexibility using sit and reach. The data analysis technique used the mean and percentage category. The results obtained are the average VO2Max value of male and female athletes in the "Good" category. The arm muscle strength of male and female athletes is still in the "Enough" category. The abdominal muscle strength of male athletes was on average in the "Good" category and female athletes in the 
"Enough" category. The reaction speed of male athletes is in the "Very Good" category while female athletes are in the "Good" category. The agility component of male and female athletes is in the "Good" category. Components of leg muscle power for male and female athletes in the "Excellent" category. The flexibility of male athletes in the "Good" category and female athletes in the "Excellent" category.

Keywords: evaluation; physical components; Karate

\section{Pendahuluan}

Pusat Pendidikan dan Latihan Pelajar (PPLP) Provinsi Gorontalo merupakan salah satu wadah pembinaan prestasi pelajar khususnya di bidang olahraga yang ada di Provinsi Gorontalo. Wadah yang berada dibawah naungan Dinas Pendidikan Kebudayaan Pemuda dan Olahraga (DIKBUDPORA) ini, secara rutin setiap tahunnya melakukan proses pembinaan bagi para atlet di beberapa cabang olahraga seperti Atletik, Sepak takraw, Tenis meja, Anggar, Karate, Pencak silat dan Taekwondo yang nantinya dipersiapkan untuk mengikuti event seperti Kejuaraan Nasional (KEJURNAS) antar PPLP/PPLPD/SKO dan Pekan Olahraga Pelajar Nasional (POPNAS).

Mengkaji tentang prestasi atlet, merupakan hal yang sangat kompleks serta membutuhkan metodologi kepelatihan yang sesuai (Mylsidayu \& Kurniawan, 2015). Terdapat beberapa aspek yang harus diperhatikan terkait dengan peningkatan prestasi atlet. Salah satu di antaranya adalah kondisi fisik (Nugroho, 2012). Komponen teknik, taknik maupun strategi akan baik digunakan dalam pertandingan maupun perlombaan, manakala ditunjang oleh baiknya status komponen kondisi fisik dan asupan gizi atlet (Aprilia, 2018). Baiknya status fisik atlet akan membantu atlet tersebut dalam menjalankan program latihannya serta dapat menghindari atlet dari resiko cedera (de Leeuw et al., 2021). Kondisi fisik merupakan faktor yang harus dimiliki setiap atlet, yang kemudian menjadi landasan untuk memperoleh kemampuan teknik dan taktik.

Terkait dengan komponen kondisi fisik, akan berbeda pada masing-masing cabang olahraga. Hal ini disebabkan oleh karena adanya perbedaan karakteristik gerak pada setiap cabang olahraga. Khususnya pada cabang olahraga Karate, terdapat beberapa komponen kondisi fisik dominan yang harus berstatus prima pada masing-masing atlet (Piepiora et al., 2016). Adapun komponen kondisi fisik yang dimaksud meliputi daya tahan aerobik dan anaerobik, kekuatan, daya tahan otot, kecepatan yang terdiri dari kecepatan gerak dan kecepatan reaksi, kelentukan, kelincahan, power, ketepatan, keseimbangan, dan koordinasi.

Melihat kompleksnya komponen fisik dominan pada cabang olahraga Karate, menuntut kejelian pelatih dalam merancang sebuah perencanaan latihan yang sesuai dengan metodologi kepelatihan. Adanya periodisasi latihan yang dijalankan oleh atlet merupakan suatu intervensi yang diberikan oleh pelatih dalam upaya meningkatkan status komponen fisik atlet ke level yang lebih baik agar nantinya bisa mencapai prestasi yang ditargetkan (Nurkadri, 2017).

Mengacu hal tersebut, perlu dilakukan suatu langkah evaluasi terkait dengan sejauh mana status komponen kondisi fisik yang dimiliki oleh atlet PPLP khususnya pada cabang Karate saat ini setelah adanya intervensi yang dimaksud. Hasil evaluasi yang dimaksud, nantinya bisa 
direkomendasikan kepada pelatih sebagai bahan evaluasi terhadap program latihan yang telah dijalankan.

Karate merupakan salah satu cabang olahraga beladiri body contact, dimana dalam pelaksanaan pertandingannya dilakukan dengan intensitas tinggi serta sangat rentan dengan terjadinya cedera (Augustovičová et al., 2019)(Pal et al., 2020). Kondisi ini pada gilirannya menuntut para atlet agar dapat mempersiapkan diri dengan sebaik-baiknya. Persiapan yang dimaksud mencakup komponen fisik, teknik, taktik maupun mental.

Pentahapan latihan dalam periodisasi latihan secara metodologi diawali dengan latihan yang bertujuan untuk meningkatkan status komponen kondisi fisik atlet (Witte et al., 2016). Hal ini dilakukan agar nantinya atlet memiliki pondasi awal dalam melanjutkan program latihan secara spesifik pada pentahapan latihan selanjutnya. Adanya dasar status komponen kondisi fisik yang baik, maka peak atau puncak prestasi akan mudah untuk dicapai oleh atlet.

Berkaitan dengan hal tersebut, periodisasi latihan yang sedang dijalankan oleh atlet Karate PPLP Provinsi Gorontalo periode tahun 2021 bertepatan dengan petahapan latihan peningkatan komponen kondisi fisik. Pentahapan latihan yang dijalankan, dilakukan guna untuk mempersiapkan atlet dalam menghadapi event Kejurnas antar PPLP/PPLPD/SKO dan Popnas di tahun 2021. Penelitian terdahulu yang bertujuan untuk mengetahui profil fisik kondisi fisik atlet Karate junior putra perguruan Inkanas kota Bengkulu tahun 2019 (Gultom et al., 2019). Maupun penelitian yang sama tempatnya di PPLP Provinsi Gorontalo menghasilkan temuan bahwa Temuan penelitian membuktikan bahwa terjadi penurunan rata-rata VO2Max atlet putri sebesar $23 \%$ dan atlet putra sebesar $18 \%$ (Kadir, 2020). Memerlukan penelitian lebih lanjut sebagai upaya pelatih dalam mengetahui kondisi fisik atletnya.

Menyikapi permasalahan tersebut, maka dipandang perlu dilakukan upaya evaluasi komponen kondisi fisik atlet Karate PPLP Provinsi Gorontalo tahun 2021, agar nantinya bisa dijadikan salah satu bahan masukan dan evaluasi terhadap atlet dan pelatih terhadap program latihan yang telah dijanlankan.

\section{Metode}

Penelitian ini merupakan penelitian deskriptif kuantitatif yang bermaksud untuk mendeskripsikan atau memberi gambaran tentang status komponen kondisi fisik atlet Karate PPLP Provinsi Gorontalo tahun 2021. Populasi yang merupakan wilayah generalisasi dalam penelitian ini yakni keseluruhan atlet Karate PPLP Provinsi Gorontalo tahun 2021 yang berjumlah 13 orang terdiri dari 5 orang putri dan 8 orang putra. Berkaitan dengan upaya pengumpulan data penelitian tentang komponen kondisi fisik atlet, peneliti menggunakan instrument tes dan pengukuran yang meliputi: 1) $\mathrm{VO}_{2} \mathrm{Max}$ menggunakan Multistage Fitness Test (Bleep Test); 2) Kekuatan otot lengan menggunakan push up selama 30 detik; 3) Kekuatan otot perut menggunakan sit up 30 detik; 4) Kecepatan reaksi menggunakan alat beem 5)

Kelincahan menggunakan shuttle run; 6) Power otot tungkai menggunakan standing board jump; dan 7) Kelentukan menggunakan sit and reach. Adapun Teknik analisis data menggunakan mean dan presentase kategori. 


\section{Hasil}

Data hasil penelitian yang ada, merupakan data terkait dengan komponen kondisi fisik dominan pada cabang olahraga Karate yang diperoleh melalui tes dan pengukuran khususnya pada atlet Karate yang tergabung dalam PPLP Provinsi Gorontalo yang berjumlah 13 orang, yang terdiri dari 8 orang atlet putra dan 5 orang atlet putri.

Adapun hasil tes tersebut akan dibagikan menjadi dua tabel yang berbeda sebagai berikut:

Tabel 1. Data Hasil Tes Atlet Karate Putra PPLP Provinsi Gorontalo

\begin{tabular}{|c|c|c|c|c|c|c|c|c|c|c|c|c|c|c|c|}
\hline \multirow{3}{*}{$\begin{array}{l}\mathbf{N} \\
\mathbf{O}\end{array}$} & \multicolumn{15}{|c|}{$\begin{array}{c}\text { HASIL DAN KATEGORI MASING-MASING KOMPONEN TES } \\
\text { BERDASARKAN NORMA }\end{array}$} \\
\hline & \multicolumn{2}{|c|}{$\mathrm{VO}_{2} \mathrm{Max}$} & \multicolumn{2}{|c|}{$\begin{array}{c}\text { Kekuatan } \\
\text { Otot } \\
\text { Lengan }\end{array}$} & \multicolumn{2}{|c|}{$\begin{array}{c}\text { Kekuatan } \\
\text { Otot } \\
\text { Perut }\end{array}$} & \multicolumn{2}{|c|}{$\begin{array}{l}\text { Kecepatan } \\
\text { Reaksi }\end{array}$} & \multicolumn{2}{|c|}{ Kelincahan } & \multicolumn{3}{|c|}{$\begin{array}{l}\text { Power Otot } \\
\text { Tungkai }\end{array}$} & \multicolumn{2}{|c|}{ Kelentukan } \\
\hline & 50,2 & $\mathrm{BS}$ & 56 & $\mathrm{~B}$ & 68 & $\mathrm{~B}$ & 0,223 & $\mathrm{~B}$ & 12,14 & $\mathrm{~B}$ & $8 ' 8$ & 2,68 & $\mathrm{BS}$ & 19,5 & $\mathrm{BS}$ \\
\hline 2 & 49,6 & $\mathrm{BS}$ & 50 & $\mathrm{C}$ & 57 & $\mathrm{~B}$ & 0,114 & $\mathrm{BS}$ & 11,71 & BS & $8^{\prime} 6$ & 2,62 & BS & 17,5 & $\mathrm{~B}$ \\
\hline 3 & 46,8 & $\mathrm{~B}$ & 52 & $\mathrm{C}$ & 50 & $\mathrm{C}$ & 0,202 & $\mathrm{~B}$ & 12,49 & $\mathrm{~B}$ & 7'9 & 2,40 & $\mathrm{~B}$ & 17,5 & $\mathrm{~B}$ \\
\hline 4 & 45,2 & $\mathrm{~B}$ & 55 & $\mathrm{~B}$ & 54 & $\mathrm{~B}$ & 0,116 & $\mathrm{BS}$ & 12,14 & $\mathrm{~B}$ & $7 ’ 4$ & 2,25 & $\mathrm{C}$ & 13,0 & $\mathrm{~K}$ \\
\hline 5 & 44,2 & $\mathrm{~B}$ & 54 & $\mathrm{C}$ & 52 & $\mathrm{C}$ & 0,119 & $\mathrm{BS}$ & 13,08 & $\mathrm{~B}$ & $8 ' 3$ & 2,52 & $\mathrm{BS}$ & 16,5 & $\mathrm{~B}$ \\
\hline 6 & 43,6 & $\mathrm{~B}$ & 57 & $\mathrm{~B}$ & 56 & $\mathrm{~B}$ & 0,116 & $\mathrm{BS}$ & 12,11 & $\mathrm{~B}$ & 7'9 & 2,40 & $\mathrm{~B}$ & 15,0 & $\mathrm{C}$ \\
\hline 7 & 43,9 & $\mathrm{~B}$ & 54 & $\mathrm{~B}$ & 57 & $\mathrm{~B}$ & 0,200 & $\mathrm{BS}$ & 12,09 & $\mathrm{BS}$ & $7 \cdot 5$ & 2,28 & $\mathrm{~B}$ & 19,5 & $\mathrm{BS}$ \\
\hline 8 & 44,2 & B & 44 & $\mathrm{C}$ & 60 & $\mathrm{~B}$ & 0,209 & BS & 13,07 & B & 6'14 & 1,87 & B & 17,0 & B \\
\hline
\end{tabular}

Berdasarkan hasil yang diperoleh khususnya pada atlet putra, terlihat bahwa terdapat 2 orang atlet yang memiliki $\mathrm{VO}_{2} \mathrm{Max}$ dalam kategori "Baik Sekali", dan sisanya (6 orang atlet) dalam kategori "Baik". Untuk kekuatan otot lengan, terdapat 4 orang atlet dalam kategori "Baik" dan 4 orang atlet lainnya termasuk dalam kategori "Cukup. Untuk data kekuatan otot perut atlet, diketahui terdapat 6 orang atlet dalam kategori "Baik" dan 2 orang atlet lainnya berada dalam kategori "Cukup". Untuk kecepatan reaksi, terdapat 6 orang atlet dalam kategori "Baik Sekali" dan 2 orang atlet pada kategori "Baik". Selanjutnya, untuk Kelincahan terdapat 2 orang atlet yang ada dalam kategori "Baik Sekali" serta 6 orang lainnya dalam kategori "Baik". Untuk power otot tungkai, terdapat 3 orang atlet dalam kategori "Baik Sekali", 4 orang atlet dalam kategori "Baik" dan hanya 1orang atlet saja yang masih termasuk dalam kategori "Cukup". Sedangkan pada komponen kelentukan, terdapat 2 orang atlet dalam kategori "Baik Sekali", 4 orang dalam kategori "Baik", 1 orang dalam kategori "Cukup" dan hanya 1 orang atlet saja yang dalam kategori "Kurang".

Tabel 2. Data Hasil Tes Atlet Karate Putri PPLP Provinsi Gorontalo

\begin{tabular}{|c|c|c|c|c|c|c|c|c|c|c|c|c|c|c|c|c|}
\hline \multirow{4}{*}{$\begin{array}{l}\mathbf{N} \\
\mathbf{O}\end{array}$} & \multirow{4}{*}{ 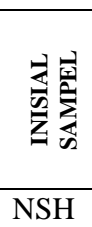 } & \multirow{2}{*}{\multicolumn{15}{|c|}{$\begin{array}{l}\text { HASIL DAN KATEGORI MASING-MASING KOMPONEN TES } \\
\text { BERDASARKAN NORMA }\end{array}$}} \\
\hline & & & & & & & & & & & & & & & & \\
\hline & & \multicolumn{2}{|c|}{$\mathrm{VO}_{2} \mathrm{Max}$} & \multicolumn{2}{|c|}{$\begin{array}{c}\text { Kekuatan } \\
\text { Otot } \\
\text { Lengan } \\
\end{array}$} & \multicolumn{2}{|c|}{$\begin{array}{c}\text { Kekuatan } \\
\text { Otot } \\
\text { Perut }\end{array}$} & \multicolumn{2}{|c|}{$\begin{array}{c}\text { Kecepatan } \\
\text { Reaksi }\end{array}$} & \multicolumn{2}{|c|}{ Kelincahan } & \multicolumn{3}{|c|}{$\begin{array}{c}\text { Power Otot } \\
\text { Tungkai }\end{array}$} & \multicolumn{2}{|c|}{ Kelentukan } \\
\hline & & 42,6 & $\mathrm{BS}$ & 47 & $\mathrm{C}$ & 47 & $\mathrm{C}$ & 0,240 & B & 12,57 & $\mathrm{~B}$ & $7 ' 5$ & 2,28 & BS & 19,0 & B \\
\hline 2 & CGA & 37,1 & $\mathrm{~B}$ & 48 & $\mathrm{C}$ & 43 & $\mathrm{C}$ & 0,217 & B & 14,72 & $\mathrm{C}$ & $6 ’ 9$ & 2,10 & BS & 20,5 & $\mathrm{BS}$ \\
\hline 3 & PYD & 38,2 & B & 55 & $\mathrm{~B}$ & 41 & $\mathrm{C}$ & 0,243 & B & 14,11 & $\mathrm{C}$ & 5,9 & 1,79 & $\mathrm{~B}$ & 19,0 & B \\
\hline 4 & MR & 36,4 & $\mathrm{~B}$ & 31 & $\mathrm{~K}$ & 47 & $\mathrm{C}$ & 0,171 & BS & 13,79 & $\mathrm{~B}$ & $7{ }^{\prime} 9$ & 2,40 & B & 17,5 & $\mathrm{C}$ \\
\hline 5 & SOT & 36.8 & $B$ & 30 & $\mathrm{~K}$ & 33 & $\mathrm{~K}$ & 0,241 & B & 14.16 & $\mathrm{C}$ & $4^{\prime} 12$ & 1,25 & $\mathrm{~K}$ & 17.5 & C \\
\hline
\end{tabular}


Data pada tabel memperlihatkan bahwa nilai $\mathrm{VO}_{2} \mathrm{Max}$ atlet Karate putri yang tergabung dalam PPLP Provinsi Gorontalo periode tahun 2021, hanya terdapat 1 orang atlet yang dalam kategori "Baik Sekali" dan sisanya yakni sebanyak 4 lainnya dalam kategori "Baik". Untuk kekuatan otot lengan, berdasarkan hasil tes ditemukan 1 dalam kategori "Baik", 2 orang dalam kategori "Cukup" dan 2 orang lainnya masih dalam kategori "Kurang". Selanjutnya, untuk kekuatan otot perut ditemukan 4 orang atlet dalam kategori "Cukup" dan sisanya (1 orang) dalam kategori "Kurang". Untuk kecepatan reaksi, terdapat 1 orang dalam kategori "Baik Sekali" dan 4 orang sisanya dalam kategori "Baik". Pada komponen Kelincahan, terdapat 2 orang dalam kategori "Baik" dan 3 orang lainnya dalam kategori "Cukup". Untuk Power otot tungkai, ditemukan 2 orang telah berada dalam kategori "Baik Sekali", 2 orang dalam kategori "Baik" dan masih terdapat 1 orang atlet dalam kategori "Kurang". Selanjutnya, pada komponen kelentukan terdapat 1 orang dalam kategori "Baik Sekali", 2 orang dalam kategori "Baik" dan 2 orang lainnya dalam kategori "Cukup".

Data hasil tes yang diperoleh dalam penelitian, selanjutnya dianalisis berdasarkan keperluan dalam penelitian. Hal ini dilakukan guna untuk memberikan makna serta memberikan kemudahan dalam upaya penarikan kesimpulan dalam penelitian yang dilakukan.

Berkaitan dengan hal tersebut, langkah awal yang dilakukan yakni menghitung nilai ratarata atau mean terhadap data hasil penelitian. Perhitungan nilai mean dilakukan pada masingmasing komponen tes. Adapun hasil perhitungan yang dimaksud, dapat terlihat pada tabel sebagai berikut:

Tabel 3. Data Hasil Perhitungan Mean Masing-Masing Komponen Tes

\begin{tabular}{|c|c|c|c|c|c|c|c|c|c|}
\hline \multirow[b]{2}{*}{ No } & \multirow[b]{2}{*}{ KOMPONEN TES } & \multicolumn{4}{|c|}{ Atlet Putra } & \multicolumn{4}{|c|}{ Atlet Putri } \\
\hline & & $\mathbf{N}$ & $\Sigma \mathbf{X}$ & $\overline{\boldsymbol{X}}$ & 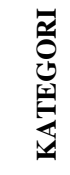 & $\mathbf{N}$ & $\Sigma X$ & $\bar{X}$ &  \\
\hline 1 & $\mathrm{VO}_{2} \mathrm{Max}$ & 8 & 36,77 & 46,0 & $\mathrm{~B}$ & 5 & 191,1 & 38,22 & $\mathrm{~B}$ \\
\hline 2 & Kekuatan Otot Lengan & 8 & 422 & 52,8 & $\mathrm{C}$ & 5 & 211 & 42,2 & $\mathrm{C}$ \\
\hline 3 & Kekuatan Otot Perut & 8 & 454 & 56,8 & $\mathrm{~B}$ & 5 & 211 & 42,2 & $\mathrm{C}$ \\
\hline 4 & Kecepatan Reaksi & 8 & 1,299 & 0,162 & $\mathrm{BS}$ & 5 & 1,112 & 0,222 & $\mathrm{~B}$ \\
\hline 5 & Kelincahan & 8 & 98,83 & 12,35 & $\mathrm{~B}$ & 5 & 69,35 & 13,87 & $\mathrm{~B}$ \\
\hline 6 & Power Otot Tungkai & 8 & 19,02 & $\begin{array}{l}2,38 \\
\left(77^{\prime} 8\right)\end{array}$ & $\mathrm{BS}$ & 5 & 9,82 & $\begin{array}{l}1,964 \\
(6,4)\end{array}$ & $\mathrm{BS}$ \\
\hline 7 & Kelentukan & 8 & 135,5 & 16,9 & $\mathrm{~B}$ & 5 & 93,5 & 18,7 & $\mathrm{BS}$ \\
\hline
\end{tabular}

Berdasarkan hasil perhitungan seperti yang tampak dalam tabel, selanjutnya dapat memberikan gambaran secara pasti terkait dengan nilai masing-masing komponen fisik dominan cabang olahraga Karate khususnya pada atlet Karate PPLP Provinsi Gorontalo periode tahun 2021.

Dari hasil perhitungan data yang dimaksud, menunjukkan bahwa terdapat 2 komponen fisik atlet Karate putra yang masuk dalam kategori "Baik Sekali" yakni kecepatan reaksi dengan 
besaran nilai rata-rata 0,162 detik dan power otot tungkai dengan besaran nilai rata-rata 2,38 meter. Selanjutnya, terdapat 4 komponen fisik dominan cabang olahraga Karate yang dalam kategori "Baik" yakni $\mathrm{VO}_{2} \mathrm{Max}$ dengan besaran nilai rata-rata 46,0 $\mathrm{ml} / \mathrm{kg} / \mathrm{min}$, kekuatan otot perut dengan besaran nilai rata-rata 56,8 (dibulatkan menjadi 57) kali, kelincahan dengan besaran nilai rata-rata 12,35 detik, dan kelentukan dengan besaran nilai rata-rata 16,9 (dibulatkan menjadi 17) $\mathrm{cm}$. Disamping itu, meskipun tidak ditemukan lagi dari ke tujuh komponen fisik dalam kategori "Kurang" dan "Kurang Sekali", namun masih terdapat 1 komponen fisik yang dalam kategori "Cukup" yakni komponen kekuatan oto lengan dengan besaran nilai rata-rata 52,8 (dibulatkan menjadi 53) kali berdasarkan norma penilaian yang digunakan.

Khususnya pada atlet putri, komponen fisik yang dalam kategori "Baik Sekali" meliputi komponen fisik power otot tungkai dengan besaran nilai rata-rata yakni 1,96 meter dan komponen fisik kelentukan dengan besaran nilai rata-rata $18,7 \mathrm{~cm}$. selanjutnya, terlihat ada 3 komponen fisik dalam kategori "Baik" yang terdiri dari $\mathrm{VO}_{2} \mathrm{Max}$ dengan besaran nilai rata-rata $38,22 \mathrm{ml} / \mathrm{kg} / \mathrm{min}$, kecepatan reaksi dengan besaran nilai rata-rata 0,222 detik dan kelincahan dengan besaran nilai rata-rata 13,87 detik. Sama halnya dengan data pada atlet putra bahwa, tidak ditemukan dari ketujuh komponen fisik dominan cabang olahraga Karate pada atlet Karate putri PPLP yang dalam kategori "Kurang” dan "Kurang Sekali". Namun, terdapat 2 komponen fisik masih yang dalam kategori "Cukup" yakni kekuatan otot lengan dengan besaran nilai ratarata 42 kali, dan kekuatan otot perut dengan nilai rata-rata yakni sebesar 42 kali.

Tabel 4. Hasil Persentase setiap Kategori pada Atlet Putra Masing-Masing Komponen Tes

\begin{tabular}{|c|c|c|c|c|c|c|c|c|c|c|c|c|c|c|c|c|c|c|c|c|c|}
\hline \multirow{4}{*}{ 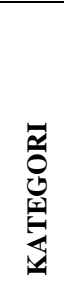 } & \multicolumn{21}{|c|}{$\begin{array}{l}\text { KOMPONEN TES DAN PENGUKURAN ATLET } \\
\text { PUTRA }\end{array}$} \\
\hline & \multicolumn{3}{|c|}{$\mathrm{VO}_{2} \mathrm{Max}$} & \multicolumn{3}{|c|}{$\begin{array}{c}\text { Kek. } \\
\text { Ot. } \\
\text { Lengan }\end{array}$} & \multicolumn{3}{|c|}{$\begin{array}{c}\text { Kek. } \\
\text { Ot. Perut }\end{array}$} & \multicolumn{3}{|c|}{ Kec. Reaksi } & \multicolumn{3}{|c|}{ Kelincahan } & \multicolumn{3}{|c|}{$\begin{array}{c}\text { Power Ot. } \\
\text { Tungkai }\end{array}$} & \multicolumn{3}{|c|}{ Kelentukan } \\
\hline & \multicolumn{3}{|c|}{ Jumlah Nilai } & \multicolumn{3}{|c|}{ Jumlah Nilai } & \multicolumn{3}{|c|}{ Jumlah Nilai } & \multicolumn{3}{|c|}{ Jumlah Nilai } & \multicolumn{3}{|c|}{ Jumlah Nilai } & \multicolumn{3}{|c|}{ Jumlah Nilai } & \multicolumn{3}{|c|}{ Jumlah Nilai } \\
\hline & $\mathbf{N}$ & $\mathbf{n}$ & $\%$ & $\mathbf{N}$ & $\mathbf{n}$ & $\%$ & $\mathbf{N}$ & $\mathbf{n}$ & $\%$ & $\mathbf{N}$ & $\mathbf{n}$ & $\%$ & $\mathbf{N}$ & n & $\%$ & $\mathbf{N}$ & $\mathbf{n}$ & $\%$ & $\mathbf{N}$ & $\mathbf{n}$ & $\%$ \\
\hline BS & & 2 & $25 \%$ & & 0 & $0 \%$ & & 0 & $0 \%$ & & 6 & $75 \%$ & & 2 & $25 \%$ & & 3 & $38 \%$ & & 2 & $25 \%$ \\
\hline B & & 6 & $75 \%$ & & 4 & $50 \%$ & & 6 & $75 \%$ & & 2 & $25 \%$ & & 6 & $75 \%$ & & 4 & $50 \%$ & & 4 & $50 \%$ \\
\hline C & 8 & 0 & $0 \%$ & 8 & 4 & $50 \%$ & 8 & 2 & $25 \%$ & 8 & 0 & $0 \%$ & 8 & 0 & $0 \%$ & 8 & 1 & $13 \%$ & 8 & 1 & $13 \%$ \\
\hline $\mathbf{K}$ & & $\overline{0}$ & $0 \%$ & & 0 & $0 \%$ & & 0 & $0 \%$ & & 0 & $0 \%$ & & 0 & $0 \%$ & & 0 & $0 \%$ & & 1 & $13 \%$ \\
\hline KS & & $\overline{0}$ & $0 \%$ & & 0 & $0 \%$ & & 0 & $0 \%$ & & 0 & $0 \%$ & & 0 & $0 \%$ & & 0 & $0 \%$ & & 0 & $0 \%$ \\
\hline
\end{tabular}

Tabel 5. Hasil Persentase setiap Kategori pada Atlet Putri Masing-Masing Komponen Tes

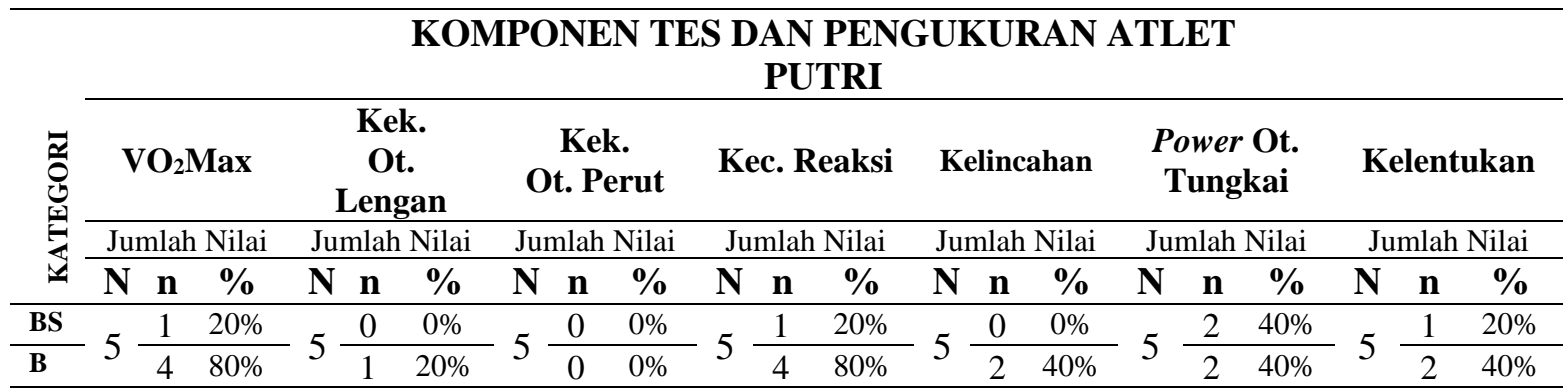




\begin{tabular}{|c|c|c|c|c|c|c|c|c|c|c|c|c|c|c|}
\hline $\mathbf{C}$ & 0 & $0 \%$ & 2 & $40 \%$ & 4 & $80 \%$ & 0 & $0 \%$ & 3 & $60 \%$ & 1 & $20 \%$ & 2 & $40 \%$ \\
\hline $\mathbf{K}$ & 0 & $0 \%$ & 2 & $40 \%$ & 1 & $20 \%$ & 0 & $0 \%$ & 0 & $0 \%$ & 0 & $0 \%$ & 0 & $0 \%$ \\
\hline KS & 0 & $0 \%$ & 0 & $0 \%$ & 0 & $0 \%$ & 0 & $0 \%$ & 0 & $0 \%$ & 0 & $0 \%$ & 0 & $0 \%$ \\
\hline
\end{tabular}

Berdasarkan hasil perhitungan nilai persentase setiap kategori pada masing-masing komponen fisik dalam tabel, dapat menggambarkan besaran persentase setiap kategori pada masing-masing komponen fisik dominan pada cabang olahraga Karate khususnya pada atlet Karate putra yang tergabung dalam PPLP Provinsi Gorontalo periode tahun 2021.

Adapun data dalam tabel yang dimaksud, menunjukkan bahwa pada komponen fisik $\mathrm{VO}_{2} \mathrm{Max}$, hanya sebesar $25 \%$ dari total atlet putra yang dalam kategori "Baik Sekali", $75 \%$ dalam kategori "Baik", dan sudah tidak ada lagi (0\%) atlet dalam kategori "Cukup", "Kurang" dan "Kurang Sekali". Pada komponen kekuatan otot lengan, belum terdapat atlet $(0 \%)$ dalam kategori "Baik Sekali". Akantetapi dari total keseluruhan atlet putra yang ada, masing-masing terbagi secara merata dalam kategori "Baik" yakni sebesar 50\% dan dalam kategori "Cukup" serta tidak terdapat lagi atlet $(0 \%)$ dalam kategori "Kurang" dan "Kurang Sekali". Untuk komponen kekuatan otot perut, belum terdapat atlet (0\%) dalam kategori "Baik Sekali", 75\% dalam kategori "Baik", 25\% dalam kategori "Cukup" dan tidak ada terdapat lagi atlet (0\%) dalam kategori "Kurang" dan "Kurang Sekali". Pada komponen kecepatan reaksi dari total keseluruhan atlet putra, tidak terdapat lagi atlet (0\%) dalam kategori "Cukup", "Kurang" dan "Kurang Sekali". Persentase pada komponen ini berada dalam kategori "Baik Sekali" yakni sebesar 75\% dan sisanya dalam kategori "Baik" yakni sebesar 25\%. Untuk komponen kelincahan, sebesar 25\% atlet dalam kategori "Baik Sekali" dan sebagian besar atau sisanya yakni sebesar 75\% dalam kategori "Baik". Demikian pula halnya pada komponen kecepatan reaksi, pada komponen kelincahan ini juga sudah tidak ada lagi atlet $0 \%$ yang dalam kategori "Cukup", "Kurang" dan "Kurang Sekali". Pada komponen power otot tungkai, sebesar 38\% atlet dalam kategori "Baik Sekali", sebesar 50\% dalam kategori "Baik", 13\% dalam kategori "Cukup", serta tidak terdapat lagi atlet (0\%) dalam kategori "Kurang" dan "Kurang Sekali". Selanjutnya pada komponen kelentukan, sebesar 25\% atlet dalam kategori "Baik Sekali", 50\% dalam kategori "Baik", masing-masing 13\% dalam kategori "Cukup" dan "Kurang" serta tidak ada lagi atlet $(0 \%)$ dalam kategori "Kurang Sekali".

Khusus perhitungan data untuk atlet putri pada tabel 4.5 di atas, komponen $\mathrm{VO}_{2} \mathrm{Max}$ sebesar 20\% dalam kategori "Baik Sekali", 80\% dalam kategori "Baik" dan tidak terdapat lagi atlet $(0 \%)$ dalam kategori "Cukup", "Kurang" dan "Kurang Sekali". Dalam hal komponen kekuatan otot lengan, belum ada atlet (0\%) yang dalam kategori "Baik Sekali". Dalam komponen fisik ini, sebesar 20\% atlet dalam kategori "Baik", 40\% dalam kategori "Cukup", 40\% dalam kategori "Kurang" dan sudah tidak terdapat lagi atlet $(0 \%)$ dalam kategori "Kurang Sekali". Untuk komponen kekuatan otot perut, belum ada atlet ( $0 \%$ ) dalam kategori "Baik Sekali" dan "Baik". Hampir secara keseluruhan (80\%) kemampuan atlet pada komponen kekuatan otot perut ini berada dalam kategori "Cukup" dan 20\% lainnya dalam kategori "Kurang" serta sudah tidak ada lagi atlet (0\%) dalam kategori "Kurang Sekali". Pada komponen kecepatan reaksi, atlet Karate putri di PPLP provinsi Gorontalo dalam kategori "Baik Sekali" 
sebesar $20 \%$ dari total atlet putri dan sebagian besarnya (80\%) dalam kategori "Baik", sedangkan dalam kategori "Cukup", "Kurang" dan "Kurang Sekali" sebesar 0\%. Selanjutnya pada komponen kelincahan, belum terdapat atlet (0\%) dalam kategori "Baik Sekali". Sebesar 40\%-nya dalam komponen ini dalam kategori "Baik", 60\% dalam kategori "Cukup" serta tidak ada lagi atlet $(0 \%)$ dalam kategori "Kurang" dan "Kurang Sekali". Untuk komponen power otot tungkai berdasarkan hasil yang diperoleh, sebesar 40\% atlet dalam kategori "Baik Sekali", 40\% dalam kategori "Baik", 20\% dalam kategori "Cukup" serta tidak terdapat atlet $(0 \%)$ dalam kategori "Kurang" dan "Kurang Sekali". Pada komponen terakhir yang di ukur yakni kelentukan, sebesar $20 \%$ atlet dalam kategori "Baik Sekali", masing-masing 40\% dalam kategori "Baik" dan "Cukup" dan sudah tidak terdapat lagi atlet (0\%) dalam kategori "Kurang" dan "Kurang Sekali".

\section{Pembahasan}

Mengacu pada hasil analisis data yang telah dilakukan, maka dapat diidentifikasi dengan jelas kualitas atau status komponen fisik dominan dalam cabang olahraga Karate, yang dalam hal ini dibatasi pada beberapa komponen yakni daya tahan jantung paru atau $\mathrm{VO}_{2} \mathrm{Max}$, kekuatan otot lengan, kekuatan otot perut, kecepatan reaksi, kelincahan, power otot tungkai dan kelentukan (Ridhwan \& Hariyanto, 2021)

Sebaran data yang diperoleh dalam penenlitian terhadap sampel, selanjutnya memberikan suatu gambaran terkait status dari setiap komponen fisik yang dimaksud. Berdasarkan data yang ada, terlihat bahwa dari ketujuh komponen fisik dominan yang dimaksud, tidak ada satupun yang dalam kategori "Kurang" dan "Kurang Sekali". Nilai $\mathrm{VO}_{2} \mathrm{Max}$ baik atlet putra maupun putri yang tergabung pada PPLP provinsi Gorontalo periode tahun 2021, masih dalam kategori "Baik". Hal ini sesuai dengan penelitian terdahulu yang menyatakan bahwa dengan menjalani latihan yang baik, kondisi fisik khususnya cabang olahraga beladiri akan semakin meningkat (Mohamad et al., 2021; Pasaribu, 2021; Ridhwan \& Hariyanto, 2021)

Selanjutnya, untuk komponen kekuatan otot lengan, baik atlet putra maupun putri masih sangat standar atau dalam kategori "Cukup". Komponen kekuatan otot perut, atlet putra telah berada dalam kategori "Baik", namun atlet putri masih dalam kategori "Cukup". Untuk komponen kecepatan reaksi, kemampuan atlet putra telah berada dalam kategori "Baik Sekali" dan untuk atlet putri masih dalam kategori "Baik".

Komponen kelincahan sama antara atlet putra dan putri yakni telah berada dalam kategori "Baik". Untuk komponen fisik power otot tungkai, atlet putra dan putri di PPLP provinsi Gorontalo periode tahun 2021 telah berada dalam kategori "Baik Sekali". Dan untuk komponen

kelentukan, kemampuan atlet putri telah berada dalam kategori "Baik Sekali" namun atlet putra secara rata-ratanya kemampuan mereka masih dalam kategori "Baik".

\section{Kesimpulan}

Dilihat berdasarkan karakteristik cabang olahraga Karate, keberadaan nilai $\mathrm{VO}_{2} \mathrm{Max}$ dalam kategori "Baik" sudah sangat cukup untuk menunjang performa atlet dalam pertandingan. Hal ini dikarenakan bahwa cabang olahraga Karate merupakan cabang olahraga yang lebih dominan 
anaerobiknya dibanding aerobiknya. Meskipun pada kenyataannya bahwa $\mathrm{VO}_{2} \mathrm{Max}$ yang baik atau daya tahan aerob yang baik merupakan dasar dalam pembentukan daya tahan anaerobik.

Kekuatan otot lengan merupakan salah satu komponen yang hendaknya diperhatikan peningkatannya terlebih bagi atlet Karate. Oleh karena berdasarkan penelitian yang menganalisis komponen-komponen teknik yang sering digunakan dalam pertandingan Karate, lebih didominasi oleh teknik pukulan dibandingkan dengan teknik tendangan. Hal ini tentunya membutuhkan dukungan yang baik dari kekuatan otot lengan dalam pelaksanaannya. Jika melihat kemampuan atau data kekuatan otot lengan atlet Karate PPLP yang dalam hal ini masih dalam kategori "Cukup", dikhawatirkan para atlet akan mudah mengalami kelelahan otot yang berlebihan pada saat pertandingan.

\section{Referensi}

A.M., A. N. (2012). Standarisasi Status Kondisi Fisik Atlet Cabor Perorangan KONI Daerah Istimewa Yogyakarta. Jorpres (Jurnal Olahraga Prestasi), 8(2), 49-63.

Aprilia, K. N. (2018). Analisis penerapan prinsip-prinsip latihan terhadap peningkatan kondisi fisik atlet bulu tangkis PPLOP Jawa Tengah tahun 2017/2018. Journal Power Of Sports, 1(1). https://doi.org/10.25273/jpos.v1i1.2210

Augustovičová, D., Lystad, R. P., \& Arriaza, R. (2019). Time-Loss Injuries in Karate: A Prospective Cohort Study of 4 Consecutive World Karate Championships. Orthopaedic Journal of Sports Medicine, 7(8). https://doi.org/10.1177/2325967119865866

de Leeuw, A. W., van der Zwaard, S., van Baar, R., \& Knobbe, A. (2021). Personalized machine learning approach to injury monitoring in elite volleyball players. European Journal of Sport Science. https://doi.org/10.1080/17461391.2021.1887369

Gultom, T. E., Sugiyanto, S., \& Defliyanto, D. (2019). Profil Kondisi Fisik Atlet Karate Junior Putra Perguruan Inkanas Kota Bengkulu Tahun 2019. KINESTETIK, 3(2). https://doi.org/10.33369/jk.v3i2.8922

Kadir, S. (2020). Evaluation Of Vo2max Atlet Karate In The Covid-19 Pandemic Era. Jambura Journal of Sports Coaching. https://doi.org/10.37311/jjsc.v2i2.7058

Mohamad, F. R., Hadjarati, H., \& Kadir, S. (2021). Tingkat Kebugaran Jasmani Resimen Mahasiswa Universitas Negeri Gorontalo Di Era Pandemi Covid-19. Jambura Health and Sport Journal, 3(2). https://doi.org/10.37311/jhsj.v3i2.11455

Mylsidayu, A., \& Kurniawan, F. (2015). Ilmu kepelatihan dasar. Bandung: Alfabeta.

Nurkadri, N. (2017). Perencanaan Latihan. JURNAL PRESTASI. https://doi.org/10.24114/jp.v1i2.8059

Pal, S., Yadav, J., Kalra, S., \& Sindhu, B. (2020). Injury profile in karate athletes- A literature review. Journal of Critical Reviews, 7(9). https://doi.org/10.31838/jcr.07.09.211

Pasaribu, A. M. N. (2021). Pelatihan Kondisi Fisik Atlet Padepokan Judo Kesatria. Jurnal Pengabdian Kepada Masyarakat UBJ, 4(2). https://doi.org/10.31599/jabdimas.v4i2.554 
Piepiora, P. A., Szmajke, A., Migasiewicz, J., \& Witkowski, K. (2016). The karate culture and aggressiveness in kumite competitors. Ido Movement for Culture. https://doi.org/10.14589/ido.16.2.5

Ridhwan, A., \& Hariyanto, E. (2021). Survei Kondisi Fisik Pencak Silat Persinas ASAD. Sport Science and Health, 3(5). https://doi.org/10.17977/um062v3i52021p327-334

Witte, K., Kropf, S., Darius, S., Emmermacher, P., \& Böckelmann, I. (2016). Comparing the effectiveness of karate and fitness training on cognitive functioning in older adults-A randomized controlled trial. Journal of Sport and Health Science, 5(4). https://doi.org/10.1016/j.jshs.2015.09.006 